\title{
Global Diagenetic Signatures of Shallow Water Carbonates: Carbon and Oxygen Isotopes
}

\author{
MEGAN ELIZABETH SMITH ${ }^{1}$ AND PETER SWART ${ }^{2}$
}

${ }^{1}$ University of Miami (RSMAS)

${ }^{2}$ University of Miami

Presenting Author: megan.smith@rsmas.miami.edu

Marine carbonate sediment cores have been extensively used for the reconstruction of paleo-environmental conditions, with isotopic proxies such as $\delta^{13} \mathrm{C}$ values being used to interpret significant global changes in the carbon cycle throughout earth's history. Shallow water carbonates are often utilized for these reconstructions due to their accessibility and long-term preservation in the geologic record. Many previous studies have identified major $\delta^{13} \mathrm{C}$ perturbations within shallow-water carbonate systems, and argued that because these signals are global they reflect true changes in the ocean carbon cycle. However, diagenetic events such as sea-level change, can result in alteration of shallow water carbonates across all ocean basins, a signal which could be misinterpreted as true global carbon shifts. Evidence of sea-level related meteoric diagenesis, resulting in a correlating carbon isotope excursion across shallow water carbonates from the Bahamas has been shown, however, correlating this record globally proved difficult as the Pacific Ocean core was not fully sampled resulting in a short record [1]. This study thus investigates shallow water carbonate cores from the Atlantic (Great Bahama Bank) and Pacific (Enewetak Atoll) Ocean basins, which have been unequivocally influenced by Pleistocene sea-level fluctuations, to establish the role of sealevel in producing $\mathrm{C}$ and $\mathrm{O}$ isotopic signals which correlate on a global scale. This comparison is of further interest because while the Great Bahama Bank did not 'keep up' with sea-level changes, the atolls in the Pacific always 'kept up' with sea-level. This allowed the Pacific atolls not only to produce carbonate buildups higher than present-day sea-level, but also for these buildups to be weathered away as sea-level fell. Furthermore, due to their close proximity to the surface, the Pacific Atolls were influenced by many more sea-level changes than for example, the Bahamas were. As a result of these fundamental differences, the diagenetic expression of the correlating $\delta^{13} \mathrm{C}$ and $\delta^{18} \mathrm{O}$ values, while being global in nature, are expressed in different ways in the two localities.

[1] Swart, P. K., \& Kennedy, M. J. (2012). Does the global stratigraphic reproducibility of $\delta 13 \mathrm{C}$ in Neoproterozoic carbonates require a marine origin? A Pliocene-Pleistocene comparison. Geology, 40(1), 87-90. 